\title{
The Contextual Setting of Health Care Prioritization in Nigeria
}

\author{
By Wanwuri Akor* \\ Gregory Maniatopoulos ${ }^{\dagger}$ \\ Luke Vale
}

\begin{abstract}
Although several different approaches to priority setting in health care, have been used throughout the world little is known about the process of prioritization in Low and Middle-Income Countries (LMICs). This study assesses the process of health prioritization in a LMIC, using Nigeria as a case study. It specifically looks at the context in which Nigerian's health policies are implemented and resources distributed. Semi-structure interviews were used to elicit responses from policy-makers on the process of health care prioritization. These responses were then analysed thematically in an iterative process. Participants $(n=22)$ were interviewed from the three tiers of the health system as well as from the private sector. The findings are grouped under three main themes: the organizational context; the financial context; and the political context. It was suggested from the findings, that though organizational frameworks and structures for prioritization existed, the political context exerted a much higher influence in determining the outcome of the process. Another key issue was the limited operationalization of roles and responsibilities as defined by law in the organization and structure of the health system. To achieve an efficient and equitable health systems, health care policymakers should be prepared to actively engage with all stakeholders, particularly the political stakeholders, to understand the underlying influences leading to the set political agenda for health.
\end{abstract}

Keywords: Context, Developing country, Health resource allocation, Nigeria, Priority setting.

\section{Introduction}

It is well understood that health care prioritization is context specific. This implies that, the setting is important in the decision-making process. This was highlighted by the Walt and Gilson (1994) policy triangle and it has also been reported in studies on prioritization (Rudan et al. 2010, Hipgrave et al. 2014). Walt and Gilson (1994), described a policy triangle in which the context was placed as one of the vertices and they used this to highlight the importance of context in the complex process of healthcare decision-making. Similarly, Rudan et al. (2010) and Hipgrave et al. (2014), in their review of studies on health care prioritization, suggested that to effectively improve the process, there was a need to understand the local context. These findings were still present despite advances in approaches to health care prioritization over time. For instance, in 2004 Mitton and Donaldson prepared a step by step guide to the application of Programme Budgeting and Marginal Analysis (PBMA), other guides and check lists have also been produced for the prioritization process. However, the utilization of these approaches in practice are limited and affected by the organizational context, as noted in the review of real world priority setting by Cromwell et al. (2015).

Nigeria, like other Low and Middle-Income Countries (LMIC), has a limited evidence base exploring the process of health prioritization. Uneke et al. (2013),

\footnotetext{
${ }^{*} \mathrm{PhD}$ Student, Institute of Health and Society, Newcastle University, UK.

${ }^{\dagger}$ Senior Research Associate, Institute of Health and Society, Newcastle University, UK.

"Health Found Chair in Health Economics, Institute of Health and Society, Newcastle University, UK.
} 
suggested that the process of prioritization in Nigeria might have resulted from chance, rather than a set out guideline or process. Regardless of whether this assertion is true or not, it is imperative to understand the role of context in arriving at these decisions. Specifically, it is important to consider the following questions: Do the contextual setting lead to the seemingly unplanned decision-making? And how does prioritisation in Nigeria differ from other LMIC? Hence, when evaluating the process of health care prioritization in Nigeria, it is necessary to understand the context in which these decisions are made.

It is also important to clarify what is meant by context or contextual setting in this paper. Contextual setting is taken to mean the factors that influence a process. It explores the relationship between the content and the context. A context in this case is the environment in which a content (health resource allocation or health policies) are made. Hence contextual settings are characteristics external to, but surrounding and influencing a process of health resource allocation. Similar definitions of context have proffered by other authors in the field of health quality improvement (Kaplan et al. 2012, Øvretveit 2011, Rousseau 1978). Guided by this understanding, contextual factors were derived from the interviews with policymakers on the process of health care prioritization using the methods described in the following section.

\section{Methodology}

Semi-structured interviews were conducted with policy-makers and hospital administrators, using the same set of open ended questions; suitably adjusted to suit the roles of the participants. Apart from the participants from the Federal Ministry of Health, all other participants were from one State in the country. All interviews were conducted by a single researcher (WA) face to face and all were audio recorded and transcribed before analysis. Prior to the onset of the interviews, written informed consent was obtained from each participant, which was signed and stored separately from the interview recordings. Consent was completed faceto-face, and the consent form was provided with an accompanying information sheet that explained the purpose and proposed conduct of the interview. In addition to the audio recording field notes were also collected during the interviews, after obtaining additional consent from the participants. The participants were offered an opportunity to opt out at any point or request that portions of the interviews be deleted. In addition to the recorded interviews, additional points were discussed but not audio recorded, and where consent was given, these points were written down by the interviewer.

Secondary sources such as policy documents and other documentary evidence such as minutes of meetings and proceedings of deliberations were also obtained from the informants as well as the Department of Policy Research and Statistics at the State level. These papers were used as supportive evidence, either to expand or contradict the data collected from the interviews.

The data from the interviews once transcribed was analysed thematically as an iterative process. Thematic analysis as described by Boyatzis (1998), served as a guideline in the process for coding the information obtained from the interview, 
this was done using NVIVO software (QRS International, NVIVO 11 Pro). NVIVO was also used as a storage system as well as a retrieval system to call up themes identified by sets or classifications. The transcribed data was uploaded to the software and each transcript was read and themes were coded as they materialized from the text. This process was repeated for all interview transcripts and previous transcripts were re-reviewed as new themes were identified in other interview transcripts. Due to time constraints, triangulation of the analysis by a second investigator or by using a different theoretical framework was not done. The coded themes were further grouped into larger themes addressing the key research questions. The results of this process are discussed below.

\section{Results/Discussion}

\section{Characteristics of Interviews and Sample Characteristics}

The length of the interview recordings ranged from 30 minutes to 1 hour (average length: 45 minutes). They were conducted in the offices of the participants, for which there were intermittent interruptions during the process. Hence most interview sessions were much longer than the recorded sessions with some having a duration of 3 hours or more excluding waiting times and interruptions. Six participants at some point requested that some portions of the recording be deleted or the recording stopped and continued after certain statements have been made. All but one participant discussed with the interviewer after the interviews on the priority setting process their personal experiences in the health system. It is worth noting at this point that the interviews conducted could be classified as "elitist" interviews. Consequently, a journalistic stance was employed, as described by Hochschild (2009), for conducting intensive and elite interviews, to maximize the limited time available and gain as much information as possible.

A total of 22 interviews were conducted. The interview participants were distributed amongst the various tiers of health facilities (Table 1).

Table 1. Distribution of Interview Participants

\begin{tabular}{|l|c|l|}
\hline \multicolumn{1}{|c|}{ Health institute } & $\begin{array}{c}\text { No of } \\
\text { interviews }\end{array}$ & \multicolumn{1}{c|}{ Positions of Respondents } \\
\hline Federal Ministry of Health & 2 & 1 Senior Director; 1 Deputy Director \\
\hline Federal Health Institution & 1 & Chief Medical Director (CMD) \\
\hline State Ministry of Health & 4 & 2 Directors; 2 Deputy Directors \\
\hline $\begin{array}{l}\text { Hospitals Management } \\
\text { Board }\end{array}$ & 4 & $\begin{array}{l}\text { CMD*, 3 Directors (*Quotes were } \\
\text { recorded as director for anonymity) }\end{array}$ \\
\hline Secondary Health Institution & 1 & Head of the institute \\
\hline Primary Health Care Board & 4 & 4 Directors \\
\hline $\begin{array}{l}\text { Local Government Health } \\
\text { Authority }\end{array}$ & 2 & 2 Medical Officers of Health (MOH) \\
\hline Primary Health Institution & 2 & 1 Doctor in charge and 1 Matron \\
\hline Private & 2 & 2 Hospital Directors \\
\hline
\end{tabular}




\section{Thematic Analysis Results}

Following the thematic analysis of the interviews, the results were organised into the following sub-headings:

- The organizational context - which examines how people work in this case make decisions because of the structure of the health system;

- The financial context - which examines the funding sources and their influence on health care prioritization; and

- The political context - which examines how politics influences the decision-making process.

\section{Organizational context}

Organizational context has been defined as having several characteristics by different authors in the field of management (Belkhamza and Azizi Wafa 2014, Porter and McLaughlin 2006, Ghoshal and Bartlett 1994). These characteristics generally describe the operational environment; that is, how they affect the way people work. These characteristics can be grouped into structural characteristics such as the organizational structure, job roles and management of human resources; as well as the social characteristics of the organization; in this case, the Nigerian health care system.

\section{Organizational Structure}

The Nigerian health care system is divided into the government health care system and the private care providers. The government health system is further divided into three tiers in line with the federal system of governance. These tiers are the Federal or National health system, the State health system which incorporates the primary and secondary health care. The third tier of government, Local Government, has some influence in the public health care and primary health care through the provision of staff and local government offices. Therefore, this section explores the relationship between these tiers of government, stakeholders' roles and influences, as well as the social process and structural characteristics of the health system.

The key stakeholders in health care prioritization can be grouped as follows: political office holders, the health policy-makers, health care workforce in managerial roles, and community representatives. The composition of these stakeholders in the decision-making cycle varies, depending on the level of health care decision-making. To understand these differences, Figure 1 illustrates the relationships between each level in the health care system and the key priority setting mechanisms. 
Figure 1. The Nigerian Health Care System

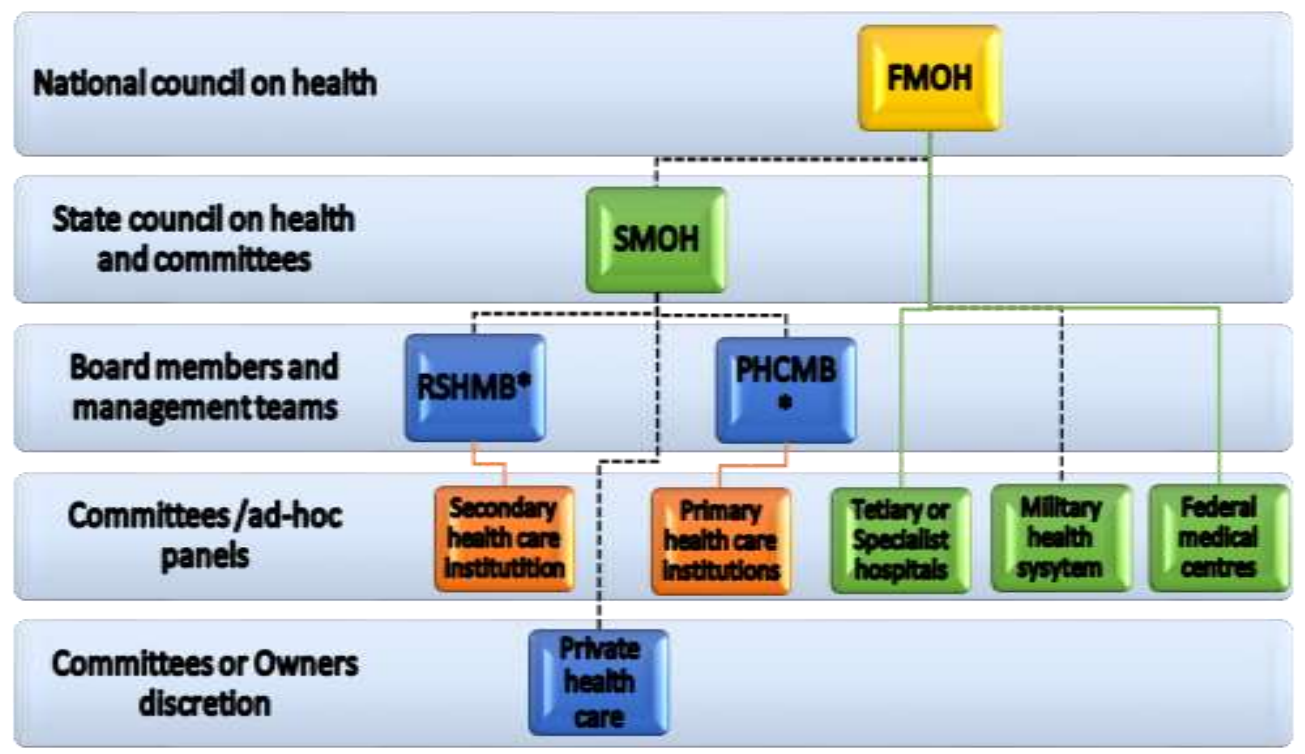

FMOH - Federal Ministry of Health; SMOH - State Ministry of Health; RSHMB - Rivers State Hospitals Management Board; PHCMB - Primary Health Care Management Board; * this split is not necessarily the same in all states.

It is important to note that whilst Figure 1 appears to show a hierarchical relationship, the actual relationship between the Federal and State Health System has been described as a strategic partnership, as the health care system in Nigeria is under a concurrent legislative list. This allows both the State and the Federal government to make health laws without reference to the other. However, where there are conflicts, Federal law supersedes the State law ${ }^{1}$. The following two comments, one from a Director in the State Ministry of Health (SMOH) and the other a Director in the Federal Ministry of Health $(\mathrm{FMOH})$ explains this point:

"... health is under the concurrent lists. So, the States have their different policies. But Federal Government is like up there. And would from time to time assist the State; from time to time make some policies and guidelines that will trickle down the State." (A Director in the SMOH)

"Nigeria as a federating unit will also take into consideration people from the States, because the Federal cannot really make policies especially health policies without the State making their input because the States are given their opportunities within the law, have the right to also make their own health policies." (A Director in the FMOH)

While this relationship between the Federal Ministry of Health (National level) and the State Ministry of Health (State level) is clearly spelt out by law and evident in their relationship, the relationship between the State level of care and the District (local government level) is unclear, as the health plans and resources for the local government level of care are managed at the State level,

\footnotetext{
${ }^{1}$ Retrieved from goo.gl/htZaK.
} 
via the primary health care board. However, there are contributions from the local government authority in the form of public health workforce and office spaces for the local health authority headed by a Medical officer of health $(\mathrm{MOH})$ employed by the State Ministry of Health. The $\mathrm{MOH}$, manages the public health workers employed by the local government and the primary health care workers employed by the State for each local government area, to carry out the State plans for health at that level, as shown below:

"... prioritizing these projects and really incorporating the budget will depend on the directors at the State level, as at the State Primary Health Care Management Board level, what they think about those inputs from the local governments. Are they going to impact positively?" (A Director in the PHCMB)

An understanding of the relationship described in the quote above is important in appreciating the complex dynamics in the health care system at this level. There is a mixture of staff by two different employers, working under the leadership of another employee, who has limited capacity to discipline half of his workforce as they are not directly employed by them. This unclear mix of staff, affects the smooth running of the health system at the local level. This can be surmised by the words of the Medical Officer of Health (MOH) in one of the Local Governments:

"... The answer is very simple. The staff that are working in the primary health care centres have to be controlled by the primary health care management board. As it stands now, primary health care board is just doing their administrative services like what I'm doing, their salary still comes from the council, so there should be a way. When there was no primary health care management board, council had the alternative to employ their own health staff in their own health centre. Now that ... there is a board, those health workers, you either regard them as your own cause they cannot be working for board and you are paying them salary, so they have to find a balance, be on the same page, who is responsible. It is who pays your salary is the person you owe loyalty to. So, I as I stand here, my queries mean nothing, it just stays in the file." (An MOH at the local health authority)

This poorly defined organizational structure is not only limited to the primary health setting at the local government level, but also at the State level relationship between the State Ministry of Health and the Hospitals Management Board (RSHMB) and the Primary Health Care Management Board (PHCMB), as well as within directorates in the State Ministry of Health. This was evident in the post interview discussions with the respondents at these levels where one Director used the term "fiefdom" and another used the phrase "grabbing things to their department". At the board level, the quote below explains the limited capacity of the Hospitals Management Board to function independent of the State Ministry of Health as its financial allocation is rarely released by the State Ministry of Health: 
"But ideally, just like the Primary Healthcare has its own allocation, we at the Hospital management board, should also have our own allocation based on our budgets. Because each year we prepare a budget, submit it and nothing comes directly to the Hospital Management Board - which is an anomaly - it shouldn't be that way." (A Director in RSHMB)

The hospitals management board by the decree forming it, is not directly under the departments in the State Ministry of Health, but has a head who reports to the Commissioner of Health, who in turn reports to the State Governor. As described in the Rivers State health profile 1999 - 2004:

"The RSHMB, amongst others, is responsible for the administration and management of hospitals that come under their jurisdiction and ensure standard national guidelines for hospitals are adhered to. The board functions under the general supervision of the Hon. Commissioner of Health." (RSMOH n.d.)

From the descriptions above, the health care system at the State level cannot be clearly separated from the district or local level of care. Furthermore, there are unclear chains of commands between and within each level of care. There is an overriding influence of the State Ministry of Health $(\mathrm{SMOH})$, which is not welcomed by the boards as it limits their capacity to effectively manage the health facilities. In the same light, the local government authority is yet to relinquish complete control of the health staff at the primary level of care to the PHCMB, the reasons for this are not clear as the research focused on health care policy-makers and did not include the political stakeholders. However, from the perspective of the health care policy-makers, it was suggested that lack of political will to effect the change might be responsible for this staff mix. Considering the poorly defined relationship that exists between the Boards and the Ministry, it is quite pertinent to question whether having a Primary Care Board is the solution to managing the Primary Health Care System since the Local Government still wields some control over its staff at that level of care. Subsequently, it is equally necessary to describe the composition of stakeholders at the various levels of decision-making, described so far.

At the boards and ministries of health, the usual stakeholders in the prioritization process are the health policy-makers, who are career civil servants, most with a degree in medicine or other allied health degrees. They are joined by political stakeholders such as the commissioner of health and politically appointed board members at the board level. There is little or no representation from the community or from patient groups. Whereas, at the institutional levels, particularly at the primary care level, there is a greater participation of community representatives, health workers and rather less frequent participation from policymakers. Bearing in mind the compositions of stakeholders at the board and institutional levels, it can be argued that a centralised process at the hospital boards, may not be as inclusive of all perspectives in its assessment of the health needs of the population. On the other hand, since the product of the prioritization 
process at the institutional level is fed into the process at the board and State ministry level, it might be described as a tiered decision-making process, in which all stakeholders are involved, in a staggered manner, reducing the administrative cost and time required in the prioritization process. Nonetheless, it is pertinent to ask: how many tiers of decision-making is needed to arrive at the final decision on resource allocation; and how do these intervening layers diminish the impact of the grass-root values and preferences in the decisions made at the end of the process?

Respondents at all level, expressed a dissatisfaction with the current process and uncertainty that their input was considered in the resultant resource allocation process.

"I have been involved in some form of planning, policy development and budgeting. But allocation, I think I am not involved." (A Director FMOH)

"I believe that when you ask the people that should tell you, they will tell you correctly ... when they are competent and qualified to tell you ... but if you don't ask, then you are a policy-maker [referencing political stakeholders], you get it wrong." (A Director SMOH)

"People just say every time that's what we write. Nothing comes out of it." (A Deputy Director SMOH)

"I have just taken part in one of such exercise but the fillers I have from those who have been on ground, the greatest challenge I think is that over the years, the inputs they make, even if it gets down to the paper ... what eventually comes out is only an insignificant portion of what is there as the budget ...." (A Director RSHMB)

"They don't come explaining to us, in fact they are the big boss, so often times they don't consider us." (A Director PHCMB)

"I don't really know how they do it ... We call a meeting, we go for strategic planning, we put for that at the end or beginning of the year they ask every unit to bring their budget, to prepare their budget for the next year and you submit and that's the end of it." (A MOH)

"So sometimes, you could actually write for some things that you need and it is not being approved." (A head of a primary care institution)

In addition to the committees described thus far in the health care decision-making process, there is an overarching decision-making body which meets yearly, with representatives from all the States, including policy-makers, health commissioners, and hospital administrators; policy-makers from the Federal Ministry of Health and the Minister of Health, Non-Governmental Organizations, International Partners, and the News Media. This body is called the National Council on Health. This council's role is to identify and agree on key national policies. At the state level, this council is replicated but it was 
described by respondents as meeting infrequently, with the last one in Rivers State held about 5 years ago at the time of this study.

As mentioned earlier, this research focussed on the health care policymakers. However, at the end of the prioritization process at this level, the final resource allocation is decided upon by the State Executive Council for the State level priority setting process (PSP) and the Federal Executive Council for the federal level PSP. These councils are made up of the elected political leaders at these levels - Governors and President, as well as appointed political leaders, representing the various ministries or departments.

"The chief executive of the board is a stakeholder [interviewer - probably of the two boards] of the two boards ... yes, the primary and the secondary, the directors at the Ministry of Health working together with the Permanent Secretary and the Honourable Commissioner, of course everything ends at the level of the executive council of the State because what the commissioner of health presents to the council, the council will look at it and come up with what they think can work." (A Director RSHMB)

"The financial resource allocation is done, first of all at the ministry and its agencies, they draw up a budget, the budget office of the federation now will allocate a particular budget based on what the executives - the federal executive council wants to allocate to health care." (A Deputy Director $\mathrm{FMOH})$

\section{Stakeholders' Roles}

The previous section looked at the mainstream health sector as an organization. It did not consider the roles of other parties' external to this organization and the relationships between these parties and the health sector. Over $60 \%$ of Nigeria's health care is provided by players external to the system described in the previous section (Palmer 2006a, Palmer 2006b). These external players include private care providers that range from registered private hospitals and clinics to traditional birth attendants and even quacks. There are policies governing the regulation of these private health care providers, in the national health act and other associated legislation as attested to by the respondents:

"We have a regulatory body; Director of Medical Services regulates the private practice. There is an enabling law that enables the regulation ... ." (A Deputy Director SMOH)

"The private hospital are much more than the government hospitals we try to put standards and ensure that those standards are met. And then we regulate what they do according to the standards. And they are required actually to give us the health records. So, with that we are able to have one unified health care system." (A Director SMOH) 
However, in practice, most respondents felt there was limited regulation of these providers.

"It's a very big gap. ... As a matter of fact, I'm not aware of any forum where we interact to the extent that they can begin to make positive inputs into what comes out as the policy direction for health." (A Director RSHMB)

"There is no clear-cut policy that instructs private health facilities to report to the office of the medical officer of health, till now. There is a law, they need to report, even before they start private practice, they need to come here, but there's no such thing, it's not enforced, anybody just opens the clinic... ." (A MOH)

To further support the view that there was limited regulation of the private sector the first registered private hospital visited for information, opened the discussion with this:

"There is really nothing to say; the government has nothing to do with us. They are not interested." (Consultant in charge of a private for-profit hospital)

On the contrary, some policy-makers felt they engaged them appropriately, while others attested to the fact that efforts were being made to incorporate them in the decision-making.

"Our collaboration has been more technical than resource mobilisation, we've been more technical because the private sector has their own sources. Sometimes they are probably richer than government, so we have not looked at it from resource mobilisation. From time to time we have had to post some manpower to strengthen an area of private endeavour in health services." (A Director SMOH)

"We have also started to engage the private sector providers through some of the associations because we want to harness all the information from what they are doing because we found that there is a gap, a lot of defect in our data and if we putting in so much effort, why is not been reflected, that means there's somewhere where people are going to get some of this treatments. ... So we are bringing them on board, then putting them into some of our programs, especially the big facilities, within the global fund support, they are working on the private sector, there is some funding from the World Bank, that supports us to engage in private sector and also we are trying within the States to get the States to ... so that we gather data from those facilities, it will help for national planning and also help us to be able to showcase statistics and information on what we are doing in the country." (A Deputy Director FMOH) 
During the interviews, the following terms as shown in the Figure 2 below were used by respondents to describe the relationship between the private health system and the government health system.

Figure 2. Government/Private Sector Relationship

\begin{tabular}{l} 
Key terms used to describe the relationship with the private sector \\
\hline Complementary \\
Technical \\
Strategic support \\
Training support \\
Regulatory \\
Controlling \\
Public private partnership \\
Unclear \\
\hline
\end{tabular}

Some respondents felt that the limited participation and inclusion of the private sector in the mainstream activity may be due to the distrust of the government by the private care providers. Here the role of the government in managing the uncertainty in the health care market is described by some respondents as running a parallel market which is subsidised for the poor. Nonetheless, there are widening inequalities and limited access for those from lower socioeconomic groups, with government facilities accessed proportionately less by those in the lowest socioeconomic class. Similar observations have been made in Peru (Kristiansson et al. 2009) and in studies in developed countries like Canada (Veugelers and Yip 2003, Olah et al. 2013).

Within the government health system, the Federal Ministry is the parent ministry and plays a strategic leadership role. It gives technical assistance to the State Ministry of Health. The State Ministry of Health gives strategic and technical support to the various boards. The health boards are the operational level of care delivery and oversee the downstream health facilities which implement the health plans and policies. Although most respondents at the board and health facilities level felt that there was an overriding influence of the State Ministry of Health as shown by the following comments:

"... Major items like so have to come through one partner and direct purchase by government because the hospital is not in a position." (A head of a secondary care institution)

"There is this thing we call up down and down up, what happens is up down not bottom up. What happens is that they will just tell you what to do so all these are formalities, you put them in a file, while they give you decisions from top, what you are doing here from the local office doesn't make any sense." (A MOH)

Generally, the relationship between the Federal and State level was described as collaborative and aligning in nature; those between the State and the Boards were described as overriding or negligent in nature: 
"The community health physicians play a lot of roles in this because they collaborate between the Federal Ministry of Health and the Federal Ministry of Health in the States, and they are coordinated." (A head of a tertiary institution)

"Sure, yes. It has to align with the National and State Strategic Plan." (A deputy director $\mathrm{SMOH}$ )

"Our supervisory board will demand a list of all we need, we will write it and send it to them, we look at it as capital projects, they are supposed to be funded directly by government through the Ministry of Health and when they don't come out, you get a donor to give you something." (A head of a secondary health care institution)

At the health facilities level where they had direct relationships with community, the relationship between the facilities and the community, was described as cordial.

Given that, in common with most LMICs, one funding sources of the health system was from international donor agencies, it was also useful to explore the relationships and roles of these funding partners. It was noted that while the relationship at the national level with these partners were described as assistive, some respondents at the State level saw their role as influential, having pre-set ideas while in some instances they were supportive, providing technical assistance. The following quote illustrates the relationship at the State level and the negotiating stance of the health policy-makers in ensuring that the health agenda of the State is not totally abandoned and replaced by that of the donor agencies.

"No, usually the problem we have is that they have their own ideas. They come with their own pre-set ideas and we usually try to come to a balance between what we want and what they want. Most of the time they come with their own fixed ideas." (A Deputy Director SMOH)

The other group of stakeholders to consider are the political stakeholders. It was noted that their influence was overriding as has been demonstrated by previous quotes. The health policy-makers, generally aligned to the health agenda of the politicians. However, there were some activities such as immunization that were inviolable, and unaffected by the changing political climate. The political context of health care prioritization is further explored in the section following the discussion on the financial context.

\section{Financial context}

Three major funding sources were identified in the interviews. These were user fees/insurance; government allocation and donations from corporate bodies or international donors. These sources differed based upon the organizational level of the interview participants. For instance, emphasis on user fees were noted at the health care institution - the Primary Health Care 
Centres and the Hospitals. However, the mechanism in which this source of funding was utilized in health resource allocation differed between institutions. While, at the Health Boards and at the Ministry of Health level, government allocation and the inputs from donors were the main sources of funding.

The funding of the health sector by user fees (out of pocket expenditure) in most LMICs is well known (van Doorslaer et al. 2006, Leive and Ke 2008). In Nigeria, the contribution of user fees to health funding is estimated by the World Bank to be $71.7 \%$ of the total health expenditure in 2014 and to represent $95.7 \%$ of private expenditure on health (Uneke et al. 2013). This agrees with the findings from the interviews, where the primary health facilities ran a requisition based funding system. That is, the health centres were funded based on incomes generated by user fees, which were then paid into a revenue account and released to the centres on request by the PHCMB:

"... We apply through the board, because we run two account system, we have the expenditure account and the revenue account. The revenue account has to do with all the monies you make. Like for instance, as the patients come, they pay, they go to the account officers, the account officers pay into the bank, I don't get the alert, the alert goes to them so at the end of the month, whatever we want to use, be it drugs, whatever, we apply and the board now sends the money into the expenditure account; that I get the alert and I get access to." (Doctor in charge of a primary care facility)

"You cannot requisite for more than what you generate. The requisition should be based on the outcome you generate. Now if you are generating 10,000 naira I cannot requisite for 15,000 or even 10,000. There must be a reserve for subsequent emergency. That is a condition the board gives. So, before we requisite something we know what is generated from the unit, for us to get back." (Matron in charge of a primary care facility)

In the secondary care system, a similar mechanism was in place. This was described as a revolving fund system. Here the facilities, unlike in primary care, had full access to the generated funds, but could only spend from it based on the agreement of a "Due Process and Revolving Fund Committee". The members of this committee were staff members of the health facility and not health board members unlike what obtains in the primary care system, where the spending decision was ultimately ratified by the Primary Care Board. The following quotes illustrates this point:

"What happens is that previously, government used to have whatever we generate to pay to the sub-treasury, then you now budget your needs on a monthly basis and you present that to get approval and ..., that system failed because once the money gets to government sub-treasury, when you come for it you will not find it and then hospitals now lack basic things to work with, we are now giving the option of making use of the revenue we generate; of course, we send record to government. So it became ... a 
revolving fund system. ... So, in a hospital like this, the money is now used in that department where it is generated and will have certain controls and regulations guiding it, so that is the revolving fund system, and that is exactly what we practice." (Head of a secondary health care facility)

Apart from the direct out of pocket expenditure as a source of income, in an interview with the head of a public-private partnership health care facility, the use of community based insurance was mentioned. The respondent noted that this mode of payment via insurance was popular amongst his clients, compared to out of pocket payments:

"There is a community health insurance scheme that is being run and is still running here ... at least we have about $80 \%$ of our clients ... so very few pay out of their pockets." (Head of a public private partnership health centre)

He also suggested that due to the availability of funds through the insurance scheme this increased the number of patients and improved the smooth running of the facility. However, funding from a community insurance scheme was not the predominant mode of payment in the other centres used in this study. Nonetheless, the findings from this model centre could serve as a case for the expansion of such insurance coverage at the community level, for primary care, to ensure improved availability of funds for the health centres. In addition to availability of funds, the risk pooling benefits of health insurance are well known (Aryeetey et al. 2016, Raza et al. 2015).

Funds were also noted as being obtained from government allocation. These funds are received through the budgeting system. This funding comes in through the Ministry of Health, to the boards and the various health institutes. It is typically used for capital projects and expenditures as well as public health programmes:

"What they do ahem (sic), from time to time, there are programs, campaigns, immunization, maternal and child health week, all that that comes all the way from the government which is been carried out in the health centres." (Doctor in charge of a primary health facility)

A similar view was expressed by a director in the hospitals management board:

"If for instance government sends say so and so amount of money and give it to the hospitals to run of course they can be able to say how we are going to prioritize these resources ... ." (A director RSHMB)

These government allocations were not always released on time or in accordance with the budget plans, giving room for leakages ("resources intended for, but not received by, frontline providers") and misappropriation of funds (Marouf 2013). The managers at each level of care, had to, in most cases reallocate these funds at their own discretion or based on the pressing demands 
at the time of release. Hence, they were not necessarily used on the activities for which it was planned they would be used for in the budgeting cycle. The quotes following highlight these points:

"we should know what the allocation might be and apart from that the people ... whoever is in charge must make sure they are faithful to carry out this program; these activities. You know sometimes we spend money on things that are not too much necessary." (A Director PHCMB)

"Another challenge is that, the budget release, fund request is different from fund approval. Even if they allocate 10 billion to you, at the end of the day or the year, you may not have gotten up to that or in some instances you may even get more than that but it may not be in the area you think you may want to address." (A Director SMOH)

Interestingly, in discussions about resource allocation and priority setting, this source of funding seemed to be the focal point on the approaches to prioritization. There was far less emphasis placed on priority setting around the use of funds obtained from user fees, or from donors. This is perhaps understandable as user fees are going to be fee for service this means they are directly paying for care provided. There is not much scope for priority setting unless there is a surplus or deficit - effectively the market is setting the priorities. However, to ensure appropriate use of resources, it might be useful to employ a holistic approach in the consideration of funding sources and allocation and reallocation of these funds. This point will be explored further in the discussion.

The other funding source available were the donations from corporate agencies as part of their community development activity and the donations from international organizations, such as The World Bank, United State Agency for International Development (USAID), The US President's Emergency Plan for AIDS Relief (PEPFAR) and other International Non-Governmental Bodies. This funding took many forms. For instance, some corporations, notably the multinational oil companies, formed alliances or partnership with government to upgrade and fund some health facilities in their area of operation.

"It's a partnership of er ... (sic) go and run ... the State will give you the man power, you will provide the resources to run. So, that was happening initially but the place started growing, it got to a stage that the State can no longer provide enough manpower, so the facility on its own have to source to provide, I told you initially that five percent of the staff we have are from the State, so the other 95\% are employed via this facility ... so initially SPDC [A multinational company] brings in the funds $100 \%$ to run. But the facility has to grow on its own because definitely we will not always depend on that fund, so the facility had to work on its own to sustain itself and usually, there is some amount of money coming from SPDC who is a major partner, to fund the salaries of the staff, but that after some time, is reducing ... ." (A head of a public private partnership health facility). 
In some other instances, they donated funds or material such as nets, cars or healthcare consumables, to assist the government health care systems. They also participated in the funding of some public health campaigns by way of donation of printed items or refreshments for such programmes. These findings can be corroborated by these comments following and the field observations during the World Malaria Day in April 2016

"Well, I want to say there are [donations], but you cannot really defend such investments, because for me, if you are investing, I should know how much you are bringing in, in terms of training, in term of capacity development, and other consumables, we should be able to quantify such items been received, but what you see here is that organizations, NGO's will come and then throw things that are actually not what you need to you and then you hear in the newspaper that you've been given what ... to the tune of this which you will be surprised that you never got, so that has been the challenge but I know that they bring in things, they being in stuffs but ... ." (A MOH)

Additionally, donor funding came in form of credits or loans as well as programme or project specific funding. This method of funding was in some cases seen as disruptive as it either encouraged vertical programme streams as opposed to health systems strengthening.

"I mention counterpart funding, clear agreement, they may have signed that funding will be so so .... I am advocating, everybody brings your own money and put in our own baskets, let's use it to solve our problems, don't tell us you have 10 million and it's only for mosquito nets meanwhile people are hungry." (A Director SMOH)

"Even though PEPFAR is supporting us with drugs and global funding, we also need to see that the country is making some commitment in providing drugs for those living with HIV." (A Director FMOH)

The quote above illustrates that most international donor funding required additional commitment from the country. This could come in the form of a counterpart funding agreement, in which the recipient country provided a portion of the fund to demonstrate commitment to the programme or it could be in form of the release of funds based on agreed milestones. However, just as the user funds were not considered in the yearly budgeting cycle, these funds from donors were not also considered in the planning process, and sometimes were not in line with the country's health agenda at the time. Nonetheless, they were always welcomed and utilized accordingly, the benefits if any, were incorporated into the overall health picture of the country.

From the information presented above, the funding sources in a developing country like Nigeria are diverse, distinct and potentially disjointed. It was difficult to ascertain the expected income for each budgeting cycle due to a wide range of factors. These factors include: 
- The limited recognition of the user fees as a major source of income by policy-makers, and the need to incorporate sustainable and accountable ways of collecting and utilizing these funds

- The limited and sporadic release of government budgetary allocation, that gives scope for misappropriation of funds and neglect of identified health priorities.

- The mechanisms of donor funding, which limits their alignment with locally identified priorities.

To further gain insight to the contextual setting of healthcare prioritization, a look at the political context of health care prioritization is provided in the next section.

\section{Political context}

Health care prioritization is value laden and hence highly political in nature. As attested by the quotes following, the overall prioritization process at the State and Federal level are dictated by the health agenda of the Honourable Commissioner of Health and the Honourable Minister of Health respectively.

"Our minister's flagship project is UHC - Universal Health Coverage through the primary healthcare system. He has done a lot of background work in identifying other sources of income to help us implement that his agenda." (A Director FMOH)

"Since I have not been where the politicians generate the agenda I wouldn't be able to say .... The ministry aligns works in that direction by prioritizing. It doesn't mean that we don't do any other thing except their priorities, but the direction of the present government usually governs prioritization ... ." (A Deputy Director $\mathrm{SMOH}$ )

The commissioner and the minister are members of the State and Federal executive council respectively and are both political appointees. Historically, such posts have been held by medical doctors or other health workers, who are not current staff of the civil service but are renowned in the field of medicine or health service delivery. This then implies that with changing governments or even cabinet reshuffles, there is a risk of changing policy direction in the health system, and a possibility for a total abandonment of the previous policy and priorities. An example would be the delay in release of a new strategic development plan by the current administration, after the elapse of the former plan prepared by the previous administration. When a deputy director in the $\mathrm{SMOH}$ was asked about the plan, the following was the response obtained:

"I am a little worried why they have not developed a new one, but it [the previous plan] has ended two months ago." (A Deputy Director SMOH) 
Apart from the role of the politicians in steering the policy direction, they also, through the State and Federal executive councils, ratify the budgets and the health plans and programmes. As expressed by some respondents, the process in which some budgets are amended at that stage is not generally inclusive of the policy-makers who drew up this budgets or plans. The reasons for changes, if any, are rarely communicated or open to appeal or amendments. This process finally ends with the signing into law of the budget or plans by the State Assembly and the National Assembly for the State and Federation, respectively. The finally decision is communicated to the health workforce via policy papers and training sessions through a SERVICOM (service compact with all Nigerians) department.

\section{Further Reflections}

The contextual setting of health care prioritization in Nigeria is primarily defined by law, as it is in most countries (Khayatzadeh-Mahani et al. 2013). Most boards and offices have pre-set roles which are either defined in the country's constitution or by the legal acts forming these bodies. However, the extent to which these definitions apply in practice are limited and less clearly defined at various levels in the health care system. In the Nigerian context, this has been noted to hamper the smooth flow of health care decision-making and resource allocation particularly with respect to human and financial resources.

Beyond the roles of the organisation and individuals are the institutions that have been set-up to support priority setting. At the State level, these are poorly utilised as evidenced by the infrequent state council on health meeting. Similarly, at the national level, there were delays in the provision of new overarching health guidelines that would define the priorities for the health sector. The impact of the limited utilisation of frameworks for priority setting was compounded by poor communication mechanisms. Similarly, bureaucratic delays, duplication of effort and limited use of priority setting institutions, along with limited application of appropriate principles and methods, have also been reported in other settings (Travis et al. 2004, Menon et al. 2007).

Another issue highlighted by this study, is the ongoing debate on whose value should guide the process? Or to put it another way, whose agenda is important? From the study findings, it was suggested that the political stakeholders led these processes and set the agenda. However, the process of developing this agenda was not explored in this study. It is pertinent to further explore the basis for the political agenda. It could be optimistically postulated that the political agenda is created to reflect the will of the masses. If this were true one might then infer that ultimately, the societal values guide the process of health prioritization. However, further exploration of this hypothesis in the health context is required.

It has been said that "he who pays the piper plays the tune", this is quite clear when considering the financial context of health care prioritization in Nigeria. The lack of a holistic and all-encompassing health financing system 
has contributed to the poor functioning of the health system as well as creating the picture of a disorganised and unplanned system (Uneke et al. 2013). Hence, despite the existence of explicit planning processes, the required financial and human resources, are rarely released by the relevant authorities' preceding each level of care, contributing to the picture of a disorganised health system. Therefore, the key issue with the Nigerian health system may not entirely lie with the lack of planning, but in the application of the plan.

Finally, health care prioritization is a highly contextual process and is context specific. However, the comparison of the findings in the literature (Bukachi et al. 2014, Byskov et al. 2014, Kamuzora et al. 2013, Maluka et al. 2011, Maluka et al. 2010, Nyandieka et al. 2015, Zulu et al. 2014, Khayatzadeh-Mahani et al. 2013, Kapiriri 2012) with the findings from a Nigerian context, show that the contextual setting of health care prioritization are not necessarily different in terms of the issues and challenges faced. Differences lie perhaps more in severity of the problem and in the guiding policy and legislations that each country adopts.

\section{Conclusion}

Health care prioritisation is value laden and is influenced by the context in which it is operationalized. As a value laden process, there is a potential for one group of stakeholders to influence the process. In this case as in most countries, it is the political stakeholders that are believed to be the key influencers. However, further studies incorporating the political stakeholders and all other identifiable stakeholders would be needed to truly identify the core influencers of the process.

\section{Acknowledgments}

We are grateful to Federal and State Ministries of Health in Nigeria for their ethics approval and helpfulness in the conduct of this study. We are also most grateful to the interview participants for their invaluable time and willingness to participate in this study.

\section{References}

Aryeetey G, Westeneng J, Spaan E, Jehu-Appiah C, Agyepong I., Baltussen R (2016) Can health insurance protect against out-of-pocket and catastrophic expenditures and also support poverty reduction? Evidence from Ghana's National Health Insurance Scheme. International Journal for Equity in Health 15(1): 116.

Belkhamza Z, Azizi Wafa S (2014) Validating the Organizational Context Measure for Collective Learning: A Managerial Action Perspective. The Learning Organization 21: 222-242. 
Boyatzis RE (1998) Transforming Qualitative Information: Thematic Analysis and Code Development. Thousand Oaks, CA.: Sage Publications.

Bukachi SA, Onyango-Ouma W, Siso JM, Nyamongo IK, Mutai JK, Hurtig AK. et al. (2014) Healthcare Priority Setting in Kenya: A Gap Analysis Applying the Accountability for Reasonableness Framework. International Journal of Health Planning and Management 29: 342-361.

Byskov J, Marchal B, Maluka S, Zulu JM, Bukachi SA, Hurtig AK. et al. (2014) The Accountability for Reasonableness Approach to Guide Priority Setting in Health Systems within Limited Resources--Findings from Action Research at District Level in Kenya, Tanzania, and Zambia. Health Research Policy and Systems 12: 49.

Cromwell I, Peacock SJ, Mitton C (2015) "Real-World" Health Care Priority Setting Using Explicit Decision Criteria: A Systematic Review of the Literature. BMC Health Services Research 15: 1-11.

Ghoshal S, Bartlett CA (1994) Linking Organizational Context and Managerial Action: The Dimensions of Quality of Management. Strategic Management Journal 15: 91-112.

Hipgrave DB, Alderman KB, Anderson I, Soto EJ (2014) Health Sector Priority Setting at Meso-Level in Lower and Middle Income Countries: Lessons Learned, Available Options and Suggested Steps. Social Science and Medicine 102: 190-200.

Hochschild JL (2009) Conducting Intensive Interviews and Elite Interviews. In: M Lamont, P White (Eds.), Workshop on Interdisciplinary Standards for Systematic Qualitative Research. Washington D.C.: National Science Foundation.

Kamuzora P, Maluka S, Ndawi B, Byskov J, Hurtig A-K (2013) Promoting Community Participation in Priority Setting in District Health Systems: Experiences from Mbarali District, Tanzania. Global Health Action 6: 22669-22669.

Kapiriri L (2012) Priority Setting in Low Income Countries: The Roles and Legitimacy of Development Assistance Partners. Public Health Ethics 5: 67-80.

Kaplan HC, Provost LP, Froehle CM, Margolis PA (2012) The Model for Understanding Success in Quality (Musiq): Building a Theory of Context in Healthcare Quality Improvement. BMJ Quality \& Safety 21: 13-20.

Khayatzadeh-Mahani A, Fotaki M, Harvey G (2013) Priority Setting and Implementation in a Centralized Health System: A Case Study of Kerman Province in Iran. Health Policy \& Planning 28: 480-494.

Kristiansson C, Gotuzzo E, Rodriguez H, Bartoloni A, Strohmeyer M, Tomson G et al. (2009) Access to Health Care in Relation to Socioeconomic Status in the Amazonian Area of Peru. International Journal for Equity in Health 8: 11.

Leive A, Ke X (2008) Coping with Out-Of-Pocket Health Payments: Empirical Evidence from 15 African Countries. Bulletin of the World Health Organization 86: 817-908.

Maluka S, Kamuzora P, Sansebastián M, Byskov J, Ndawi B, Olsen ØE et al. (2011) Implementing Accountability for Reasonableness Framework at District Level in Tanzania: A Realist Evaluation. Implementation Science 6.

Maluka S, Kamuzora P, Sebastian MS, Byskov J, Olsen OE, Shayo E et al. (2010) Decentralized Health Care Priority-Setting in Tanzania: Evaluating Against the Accountability for Reasonableness Framework. Social Science and Medicine 71: 751-759.

Marouf F (2013) Holding the World Bank Accountable for Leakage of Funds from Africa's Health Sector. Health and Human Rights Journal 12(1). Retrieved from goo.gl/yc3GTk. [Accessed: 12 May 2017]

Menon D, Stafinski T, Martin D (2007) Priority-Setting for Healthcare: Who, How, and Is It Fair? Health Policy 84(2-3): 220-233. 
Mitton C, Donaldson C (2004) Health Care Priority Setting: Principles, Practice And Challenges. Cost Effectiveness and Resource Allocation 2(3).

Nyandieka LN, Kombe Y, Byskov J, Njeru MK (2015) An Assessment of Priority Setting Process and Its Implication on Availability of Emergency Obstetric Care Services in Malindi District, Kenya. Pan African Medical Journal 22.

Olah ME, Gaisano G, Hwang SW (2013) The Effect of Socioeconomic Status on Access to Primary Care: An Audit Study. Canadian Medical Association Journal 185: E263-E269.

Øvretveit J (2011) Understanding the Conditions for Improvement: Research to Discover Which Context Influences Affect Improvement Success. BMJ Quality Safety 20: I18-I23.

Palmer N (2006a) An awkward threesome - donors, governments and non-state providers of health in low income countries. Public Administration and Development 26: 231240.

Palmer N (2006b) Non State Providers of Health Services. Retrieved from goo.gl/iGuvfd.

Porter LW, Mclaughlin GB (2006) Leadership and the Organizational Context: Like the Weather? The Leadership Quarterly 17: 559-576.

Raza W, Van De Poel E, Bedi A, Rutten F (2015) Impact of Community-Based Health Insurance on Access and Financial Protection: Evidence from Three Randomized Control Trials in Rural India. Health Economics 25(6): 675-687.

Rousseau DM (1978) Characteristics of Departments, Positions, and Individuals: Contexts for Attitudes and Behavior. Administrative Science Quarterly 23: 521-540.

RSMOH Rivers State Health Profile 1999-2004. Retrieved from goo.gl/LZqqbG.

Rudan I, Kapiriri L, Tomlinson M, Balliet M, Cohen B, Chopra M (2010) EvidenceBased Priority Setting for Health Care and Research: Tools to Support Policy in Maternal, Neonatal, and Child Health in Africa. PLOS Medicine 7.

Travis P, Bennett S, Haines A, Pang T, Bhutta Z, Hyder AA et al. (2004) Overcoming Health-Systems Constraints to Achieve the Millennium Development Goals. Lancet 364(9437): 900-906.

Uneke CJ, Ezeoha AE, Ndukwe CD, Gold Oyibo P, Onwe F, Kaur Aulakh B (2013) Research Priority Setting for Health Policy and Health Systems Strengthening in Nigeria: The Policymakers' and Stakeholders' Perspective and Involvement. Pan African Medical Journal 16(10).

Van Doorslaer E, O'donnell O, Rannan-Eliya RP, Somanathan A, Adhikari SR, Garg $\mathrm{CC}$ et al. (2006) Effect of Payments for Health Care on Poverty Estimates in 11 Countries in Asia: An Analysis of Household Survey Data. The Lancet 368: 1357-1364.

Veugelers PJ, Yip AM (2003) Socioeconomic Disparities in Health Care Use: Does Universal Coverage Reduce Inequalities in Health? Journal if Epidemiology and Community Health 57: 424-428.

Walt G, Gilson L (1994) Reforming the Health Sector in Developing Countries: The Central Role of Policy Analysis. Health Policy and Planning 9: 353-370.

Zulu J, Michelo C, Msoni C, Hurtig A-K, Byskov J, Blystad A (2014) Increased Fairness in Priority Setting Processes within the Health Sector: The Case of Kapiri-Mposhi District, Zambia. BMC Health Services Research 14: 1-12. 
